\title{
Multichannel polymer scaffold seeded with activated Schwann cells and bone mesenchymal stem cells improves axonal regeneration and functional recovery after rat spinal cord injury
}

\author{
Er-zhu YANG ${ }^{1, \#}$, Guo-wang ZHANG ${ }^{1, \#}$, Jian-guang $X^{1, *}$, Shuai $\mathrm{CHEN}^{2}$, Hua WANG ${ }^{3}$, Liang-liang $\mathrm{CAO}^{1}$, Bo LIANG ${ }^{1}$, \\ Xiao-feng LIAN $^{1, *}$ \\ ${ }^{1}$ Department of Orthopedic Surgery, Shanghai Jiao Tong University Affiliated Sixth People's Hospital, Shanghai 200233, China; \\ ${ }^{2}$ Department of Neurology, Zhengzhou University People's Hospital, Zhengzhou 450003, China; ${ }^{3}$ Department of Anesthesiology, \\ Shanghai Jiao Tong University Affiliated Sixth People's Hospital, Shanghai 200233, China
}

\begin{abstract}
The adult mammalian CNS has a limited capacity to regenerate after traumatic injury. In this study, a combinatorial strategy to promote axonal regeneration and functional recovery after spinal cord injury $(\mathrm{SCl})$ was evaluated in adult rats. The rats were subjected to a complete transection in the thoracic spinal cord, and multichannel scaffolds seeded with activated Schwann cells (ASCs) and/or rat bone marrow-derived mesenchymal stem cells (MSCs) were acutely grafted into the 3-mm-wide transection gap. At 4 weeks posttransplantation and thereafter, the rats receiving scaffolds seeded with ASCs and MSCs exhibited significant recovery of nerve function as shown by the Basso, Beattie and Bresnahan (BBB) score and electrophysiological test results. Immunohistochemical analyses at 4 and 8 weeks after transplantation revealed that the implanted MSCs at the lesion/graft site survived and differentiated into neuron-like cells and co-localized with host neurons. Robust bundles of regenerated fibers were identified in the lesion/graft site in the ASC and MSC co-transplantation rats, and neurofilament 200 (NF) staining confirmed that these fibers were axons. Furthermore, myelin basic protein (MBP)-positive myelin sheaths were also identified at the lesion/graft site and confirmed via electron microscopy. In addition to expressing mature neuronal markers, sparse MSC-derived neuron-like cells expressed choline acetyltransferase (ChAT) at the injury site of the ASC and MSC co-transplantation rats. These findings suggest that co-transplantation of ASCs and MSCs in a multichannel polymer scaffold may represent a novel combinatorial strategy for the treatment of spinal cord injury.
\end{abstract}

Keywords: spinal cord injury; PLGA scaffold; Schwann cells; bone mesenchymal stem cells; axonal regeneration

Acta Pharmacologica Sinica (2017) 38: 623-637; doi: 10.1038/aps.2017.11; published online 3 Apr 2017

\section{Introduction}

Spinal cord injury (SCI) has an immediate and irreversible impact on motor, sensory, and autonomic functions by disconnecting neural circuits above and below the lesion site. There is limited regeneration of loss tissue after central nervous system (CNS) injury in adult mammals, and the formation of a glial scar and cavity at the lesion site inhibits axonal regrowth ${ }^{[1-4]}$. The pathophysiology of spinal cord injury is a highly complex process that involves primary and second-

\footnotetext{
\# These authors contributed equally to this work.

* To whom correspondence should be addressed.

E-mail xf909@126.com (Xiao-feng LIAN); jgxu@sjtu.edu.cn (Jian-guang XU)

Received 2016-11-07 Accepted 2017-01-23
}

ary injuries, and the underlying mechanisms have not been definitively established ${ }^{[5-7]}$. Therapeutic interventions to treat SCI remain limited, and various strategies have been tested in animal models ${ }^{[8-10]}$. Previous studies have shown that transplantation of several different types of precursor/stem cells promoted axonal regeneration and functional recovery in animal models of $\mathrm{SCI}^{[11-16]}$. Among these precursor/stem cells, bone marrow mesenchymal stem cells (MSCs) are considered to be the most promising candidate for cellular transplantation and spinal cord repair because these cells may give rise to neurons and be easily isolated, expanded, and delivered ${ }^{[17,18]}$. The transplantation of MSCs into spinal cord lesions exhibits distinct effects on the recovery of injured spinal cords ${ }^{[19-21]}$. However, studies have shown that only a small proportion of MSCs differentiate into neural cells in vitro, and the implanta- 
tion of MSCs alone in vivo does not improve functional recovery $^{[22,23]}$.

Since German physiologist Theodor Schwann (1810-1882) first described the Schwann cell (SC), it has been one of the most widely studied cell types for spinal cord repair. This is because CNS glial cells, particularly astrocytes, inhibit axonal regeneration in response to injury ${ }^{[2]}$, and SCs, the myelinating cells of the peripheral nervous system (PNS), strongly promote the growth of regenerating axons ${ }^{[24]}$. SCs contribute to nerve regeneration in both the PNS and CNS by secreting a substantial variety of neurotrophic factors, including neurotrophins, which are key to modulating neuronal survival and axonal growth and providing physical support to ensheathing and myelinating growing axons ${ }^{[25-27]}$. SCs exhibit substantial potential for the repair of the injured spinal cord ${ }^{[28,29]}$. Injury to the PNS produces a cascade of cellular and molecular events, which promote the proliferation and activation of SCs within the distal nerve stump ${ }^{[24,30]}$. Activated SCs (ASCs) express various neurotrophic factors and cell adhesion molecules and supply the extracellular matrix, which plays an important role in remyelination and interactions between SCs and axons ${ }^{[31-35]}$. Compared with SCs, ASCs enhance axonal regeneration in SCI models and significantly promote functional recovery ${ }^{[36,37]}$. Co-culture of activated or preconditioned SCs with MSCs in vivo and in polymer conduits promotes MSC differentiation into neuron-like cells ${ }^{[38,39]}$.

Tissue engineering with biomaterial scaffolds has brought novel possibilities for the treatment of spinal cord injury ${ }^{[9,16]}$. Several types of synthetic biodegradable polymers have been tested, including poly (glycolic acid) (PGA), poly (L-lactic acid) (PLLA), poly ( $\varepsilon$-caprolactone) (PCL) and poly (lactic-coglycolic acid) (PLGA). PLGA is one of the most commonly used biodegradable synthetic biomaterials for tissue engineering because of its ease of fabrication, mechanical strength, and biodegradability. The pathophysiology of SCI is multifactorial and multiphasic; thus, there is no single approach that may effectively treat $\mathrm{SCI}^{[5,7]}$. An efficacious therapeutic strategy for repair following SCI will require the integration of scaffolds, stem cells, and neurotrophic factors ${ }^{[8,40,41]}$.

In the present study, the effects of a combinatorial strategy for the treatment of SCI were investigated in adult rats. A multiple-channel PLGA scaffold that contained grafted ASCs and MSCs was fabricated and implanted into a 3-mm thoracic segment of the spinal cord after complete transection and removal of the segment.

\section{Materials and methods Animal care}

All experimental procedures were approved by and performed in accordance with the standards of the Experimental Animal Center of Shanghai Jiao Tong University. Sprague-Dawley female rats were used in this study, and they were maintained under standard housing conditions. Food and water were provided ad libitum. Eight-week-old and 1-week-old SpragueDawley rats were sacrificed for isolation of ASCs and MSCs, respectively. Adult female rats that weighed 250-300 g were used for the SCI models. The rats were anesthetized using $1 \%$ pentobarbital sodium (40 mg/ $\mathrm{kg}$ ip).

\section{Preparation of PLGA scaffolds}

A PLGA scaffold with 50 micro-channels in the 3-mmdiameter conduit was fabricated as described in our previous study ${ }^{[42]}$. Briefly, a blend of poly(lactic-co-glycolic acid) (lactide $/$ glycolide $=85 / 15$ ) materials was melted at $250^{\circ} \mathrm{C}$, spun to a diameter of $25 \mu \mathrm{m}$ using a spinning machine (Shanghai Jinwei Machinery Manufacturing Co, Ltd, China), and subsequently braided to fine wires by a braider (Shanghai Xianghai Braiding Machine Co, Ltd, China). The materials were braided to micro-channels with a diameter of $100 \mu \mathrm{m}$, and every 50 micro-channels were braided to a scaffold with an outer diameter of $3 \mathrm{~mm}$. Every polymer scaffold was trimmed into a rod shape of $5 \mathrm{~cm}$ in length and $3 \mathrm{~mm}$ in diameter. The microchannels and scaffolds were disinfected using ethylene oxide, vacuum-packaged, and cold-stored at $-4^{\circ} \mathrm{C}$. Upon seeding cells into the PLGA scaffold for in vitro culture or in vivo transplantation, the PLGA rod was cut into 3-mm-thick transverse slices (Figure 1A, 1B).

\section{Isolation and culturing of ASCs}

The method for generating purified cultures of ASCs has been adapted from previous reports with modifications ${ }^{[43]}$. Briefly, the right sciatic nerves of 8 -week-old rats were cut near the hip joint for 1 week to activate SCs. The distal stumps of the cut sciatic nerves were subsequently dissected. The epineurium was stripped off to remove the connective tissue, and the remaining nerve tissue was cut into 2- to 3-mm fragments. The nerve fragments were digested with $0.16 \%$ collagenase (Invitrogen, US) for $15 \mathrm{~min}$ at $37^{\circ} \mathrm{C}$ and subsequently replaced with culture medium composed of DMEM/F-12 and 10\% fetal calf serum (Gibco, DF12-10\% FCS). The cell suspension was filtered through a $40-\mu \mathrm{m}$ cell strainer (Becton Dickinson, US) to remove residual debris, centrifuged at $400 \times g$ for 10 min, and the supernatant was discarded. The cell pellet was resuspended in DF12-10\% FCS supplemented with $5 \mu \mathrm{mol} / \mathrm{L}$ forskolin (Sigma) and $1 \mu \mathrm{g} / \mathrm{mL}$ bFGF (Sigma) and plated on disks pre-coated with poly-L-lysine (PLL, $0.1 \mathrm{mg} / \mathrm{mL}$ ) at $37^{\circ} \mathrm{C}$ in $5 \% \mathrm{CO}_{2}$ for $5 \mathrm{~d}$, followed by observation under a microscope. The cultures were subsequently fed twice per week with serum-containing DF12-10\% FCS supplemented with 5 $\mu \mathrm{mol} / \mathrm{L}$ forskolin (Sigma) and $1 \mu \mathrm{g} / \mathrm{mL}$ bFGF (Sigma). Cells were purified based on the differential velocity adherence. The percentage of S100- $\beta$-positive cells in our culture system is more than $95 \%$.

\section{Isolation and culture of MSCs}

MSCs were collected from femurs and tibias. Briefly, 1-weekold rats were sacrificed, and their femurs and tibias were removed with surgical scissors. After cutting the epiphyses of the femurs and tibias, the marrow was collected by flushing canals with DMEM (Gibco) supplemented with 10\% FCS (Gibco). The flushed solution was collected and plated in $75-\mathrm{cm}^{2}$ flasks. After $24 \mathrm{~h}$, the non-adherent cells were removed 

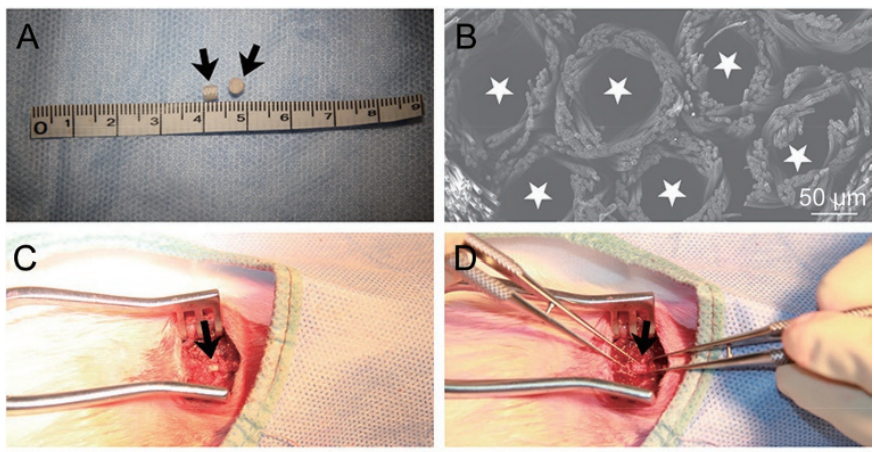

$\mathrm{E}$

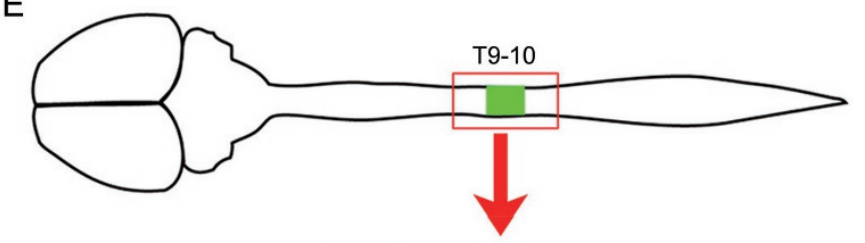

F

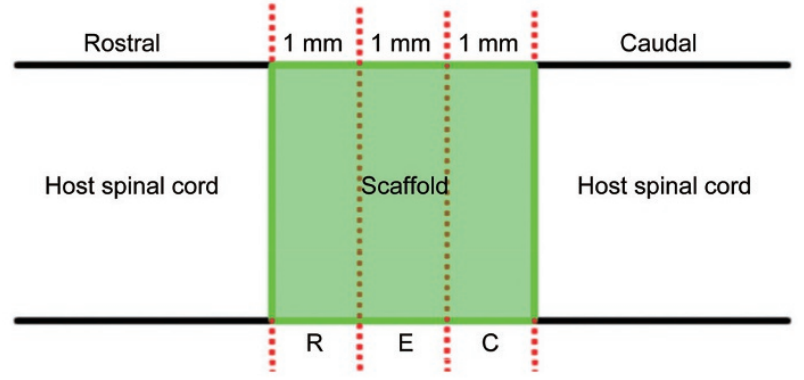

Figure 1. Surgical procedures of scaffolds transplantation and diagram of the completely transected $\mathrm{SCl}$ model. (A) Photograph of the multichannel PLGA scaffolds with a diameter of $3 \mathrm{~mm}$, cut into slices $3 \mathrm{~mm}$ thick. (B) SEM image of the transverse section of the multichannel PLGA scaffold. There are 50 micro-channels (stars) with diameters of $100 \mu \mathrm{m}$. (C) The exposed spinal cord (arrow) at T9-T10 level. (D) A 3-mm spinal cord segment was completely removed and the same size scaffold (arrow) was inserted into the corresponding gap. (E, F) Schematic diagram of completely transected $\mathrm{SCl}$ model with a 3-mm lesion/graft area, divided into R, $\mathrm{E}$, and $\mathrm{C}$ segments.

by replacing the medium (DMEM-10\% FCS). The medium was replaced every $2-3 \mathrm{~d}$ as the cells were grown to confluency.

\section{Co-culture of ASCs with MSCs in scaffolds}

To visualize implanted cells in vitro, MSCs were pre-labeled with Hoechst 33342 (Sigma). Prior to seeding on the scaffolds and co-culturing with ASCs, MSCs were incubated with Hoechst 33342 for $2 \mathrm{~h}$. Two experimental groups were designed in PLGA scaffolds: the MSCs alone group and the ASCs with MSCs co-culture group. The density of the cell suspension was adjusted to $1 \times 10^{7}$ cells $/ \mathrm{mL}$, and the cell number of ASCs versus MSCs in the co-culture group was 1:1. The volume of cell suspension added was $10 \mu \mathrm{L}$ per scaffold. To facilitate cell seeding, a filter paper was placed underneath the scaffold to gently draw cells into the channels. The scaffolds with seeded cells were subsequently incubated in a humidi- fied atmosphere at $37^{\circ} \mathrm{C}$ for $15 \mathrm{~min}$ in a 24 -well plate (1 scaffold per well) prior to being submerged in culture medium. The culture medium was changed every $2 \mathrm{~d}$. At 3, 5, 7 and $14 \mathrm{~d}$ after culture, some scaffolds in each group were fixed in $4 \%$ paraformaldehyde in $0.1 \mathrm{~mol} / \mathrm{L} \mathrm{PBS} \mathrm{(pH} \mathrm{7.4)} \mathrm{for} 2 \mathrm{~h}$ and subsequently maintained in $0.1 \mathrm{~mol} / \mathrm{L}$ PBS that contained $30 \%$ sucrose for $48 \mathrm{~h}$ at $4^{\circ} \mathrm{C}$. The scaffolds were embedded in optimum cutting temperature (OCT) compound at room temperature, frozen and sliced transversely at 30- $\mu \mathrm{m}$ thickness with a cryostat microtome. The differentiation of MSCs into neuronlike cells was detected via immunocytochemistry (ICC) of the MSC alone groups and co-culture groups. The morphology of the cells on the PLGA scaffolds was also examined under a cryo-scanning electron microscope (cryo-SEM, resolution-10 nm) (Hitachi S-4300).

\section{Spinal cord transection and transplantation}

Briefly, the adult rats were anesthetized and placed prone on a heating pad with the anterior and posterior legs stretched. The midthoracic region was shaved and disinfected with Betadine. A longitudinal incision of approximately $2.5 \mathrm{~cm}$ was subsequently made over the midthoracic region. The muscles overlying the vertebral column were reflected, which exposed the vertebral column, and a laminectomy was performed at T9-T10 (Figure 1C). The dura was cut using microforceps and microscissors, the spinal cord was lifted using a small hook (made in house), and a 3-mm segment of the spinal cord at the T10 level was removed using thin scissors. The blade was scraped repeatedly along the ventral surface of the spinal canal to verify complete transection.

Rats were divided into five groups. In the scaffold alone (ES) group $(n=12)$, a 3-mm-long empty PLGA scaffold was implanted into the lesion area. In the AS group $(n=12)$, a 3-mm-long PLGA scaffold seeded with ASCs was implanted into the lesion area, whereas in the MS group $(n=12)$, MSCs were seeded in the scaffold prior to implantation. In the AS+MS group $(n=12)$, a 3-mm-long PLGA scaffold seeded with ASCs and MSCs was implanted into the lesion area. The rats without PLGA scaffold transplantation but with a 3-mm spinal cord segment removed were used as the lesion control (SCI) group $(n=12)$. We used bromodeoxyuridine (BrdU, Sigma) to pretreat MSCs in vitro before the graft. The MSCs used in the transplantation were cultured with BrdU $(5 \mu \mathrm{g} /$ $\mathrm{mL}$ ) for $48 \mathrm{~h}$. After careful washing, the pre-labeled MSCs and the ASCs were trypsinized and suspended at $1 \times 10^{7}$ cells/ $\mathrm{mL}$ for implantation. A total of $1 \times 10^{5}$ cells in $10 \mu \mathrm{L}$ culture medium were seeded to each scaffold. In the AS+MS group, MSCs and ASCs were present at a 1:1 ratio.

After surgery, the rats were kept warm and placed on beds of sawdust. To prevent infections, penicillin $\left(50000 \mathrm{U} \cdot \mathrm{kg}^{-1} \cdot \mathrm{d}^{-1}\right)$ was injected (im) for $5 \mathrm{~d}$. The rat bladder was manually pressed three times daily until an autonomous reflex bladder emptying was established.

A subset of rats in the AS+MS group $(n=4)$ received retransection in the middle of the lesion/graft site at 8 weeks after the first operation. 


\section{Assessment of locomotor function}

Motor behavior was tested prior to surgery, at $3 \mathrm{~d}$, and each week after the operation. Two independent observers who were blinded to the treatment methods and groups performed Basso, Beattie and Bresnahan (BBB) scoring in an open field test and the inclined grid climbing test following previous reports $^{[44,45]}$. These tests included 8 rats per group and were conducted to evaluate the restoration of hindlimb locomotor function after SCI. For the BBB scoring, the rats were individually placed in an open area with a non-slippery surface and allowed to move freely for $5 \mathrm{~min}$. Two observers evaluated locomotion during open-field walking and scored the hindlimb performance according to the BBB scale in which scores range from 0 (no movement) to 21 (normal movement). For the climbing test, the rats had to move their bodies using the forelimb plus hindlimb reflexes to reach the top of the grid. This test was implemented solely to monitor the hindlimb capability of performing the placing reflex spontaneously. All behavioral evaluations were video-taped, and two investigators blinded to the treatments evaluated the functional outcome for each animal by reviewing the videotapes, with a specific focus on the hindlimb stepping, body weight support, accurate plantar placement of the paw, forelimb and hindlimb coordination, and trunk stability.

\section{Electrophysiological studies}

The somatosensory evoked potential (SEP) and motor evoked potential (MEP) were tested for each group $(n=6)$ prior to the operation and at 2, 4, and 8 weeks after the operation. The SEP and MEP comprehensively reflect the sensory and locomotor functions during the recovery process. The electrophysiological data obtained prior to the operation served as a normal control, and the latencies and amplitudes of the SEP and MEP were initially calibrated and then recorded as our standardized protocols. The rats were anesthetized, and their limbs were abducted and fixed on a rat board by cloth bands. A Key-Point evoked potential/electromyography (Medtronic, US) was used to assess the MEP and SEP of the experimental rats. The latencies and amplitudes of the SEP and MEP were recorded and transferred to a computer for the statistical analysis.

\section{Tissue processing}

Rats were sacrificed under deep anesthesia via 1\% pentobarbital sodium ( $50 \mathrm{mg} / \mathrm{kg}$, ip) at the end of 4 or 8 weeks after the transplantations. The rats were then transcardially perfused with $0.9 \%$ cold $\mathrm{NaCl}$ that contained $0.002 \%$ heparin, followed by $4 \%$ paraformaldehyde. The brain and spinal cord were subsequently excised, fixed at $4{ }^{\circ} \mathrm{C}$ in fixing solution for $6-8 \mathrm{~h}$, and maintained in a $30 \%$ sucrose solution (with $0.1 \mathrm{~mol} / \mathrm{L}$ PBS) overnight. The spinal cord tissue, including the lesion area, was embedded in OCT compound; these frozen tissue specimens were sliced longitudinally with a cryostat microtome to produce $30-\mu \mathrm{m}$ sections. All sections were divided into three groups: group 1 for $\mathrm{H} \& \mathrm{E} / \mathrm{Nissl}$ staining, group 2 for immunohistochemical staining [neurofilament 200 (NF) to confirm neural tissues and glial fibrillary acidic protein (GFAP) for scar tissues], and group 3 for double immunofluorescence staining.

\section{Immunohistochemistry}

The primary antibodies included mouse or rabbit anti- $\beta$ tubulin 3 (1:200, Sigma) to label immature neurons; rabbit antinestin (1:100, Abcam) to label neural progenitor cells (NPCs); rabbit anti-GFAP (1:500, Abcam) to label astrocytes; rabbit anti-microtubule-associated protein 2 (MAP 2, 1:500, Sigma) to label mature neurons; rabbit anti-neurofilament 200 (NF, 1:200, Sigma) to label neural tissues; rabbit anti-myelin basic protein (MBP, 1:100, Santa Cruz); rabbit anti-choline acetyltransferase (ChAT, 1:800, Abcam); and mouse anti-bromodeoxyuridine (BrdU, 1:200, Sigma) to label implanted MSCs.

For the in vitro study, samples were stained via immunofluorescence using rabbit anti-nestin, anti- $\beta$-tubulin 3 and antiMAP 2. After blocking with $10 \%$ goat serum, the cell samples were incubated with the respective primary antibodies. Cy3conjugated goat anti-rabbit IgG (1:300, Jackson Laboratory) was used as the secondary antibody. Cy3-labeled cells (red, for MAP 2, $\beta$-tubulin 3, and nestin) were evaluated under a fluorescence microscope (Nikon).

For the in vivo study, sections were immunostained for NF and GFAP and doubly labeled for nestin and BrdU, $\beta$-tubulin 3 and BrdU, nestin and $\beta$-tubulin 3, MAP 2 and BrdU, ChAT and BrdU, or MBP and BrdU. Cy3-conjugated goat anti-rabbit, anti-mouse IgG and Alexa488-conjugated goat anti-rabbit IgG (1:400, Jackson Laboratory) were used as the secondary antibodies. The sections were counterstained with 4',6-diamidino-2-phenylindole (DAPI, Santa Cruz) and observed under a fluorescence microscope (Nikon).

\section{Electron microscopy}

\section{Microstructure of scaffolds}

Sectioned scaffolds were attached to sample stubs, sputtercoated with gold/palladium, and visualized with a Hitachi S-4300 scanning electron microscope (SEM), using an accelerating voltage of $15 \mathrm{kV}$.

\section{Cell morphology on PLGA scaffolds}

After the cells were cultured in the scaffold and at different points in time, some scaffolds were observed under a cryoSEM. First, the PLGA scaffold with cells inside was mounted on an appropriate holder, plunge frozen in slushy nitrogen for $30 \mathrm{~s}$, and subsequently transferred under vacuum onto the cool stage of the cryo-SEM preparation chamber of the Quorum 2100. After sputter-coating with gold/palladium, the specimen was visualized with a Hitachi S-4300 SEM.

\section{Ultrastructure of the regenerated tissue}

After the rats were transcardially perfused with $4 \%$ paraformaldehyde plus $1 \%(w / v)$ glutaraldehyde, the brain and spinal cord were excised and subsequently fixed in $2.5 \%$ glutaraldehyde at $4^{\circ} \mathrm{C}$ for $2 \mathrm{~h}$. The regenerated tissues in the rostral, epicenter, and caudal sections of the lesion area were 
immersed in $1 \%$ osmium tetroxide for $2 \mathrm{~h}$, washed several times with $0.1 \mathrm{~mol} / \mathrm{L}$ PBS, dehydrated with gradient alcohol and acetone, and embedded in epoxy resin. Semi-thin (1- $\mu \mathrm{m})$ sections were stained by toluidine blue and observed under a light microscope. Ultra-thin (70-nm) sections were cut in an Ultrostainer (Leica) and stained with 3\% uranium acetate-lead citrate. These sections were observed under a Hitachi JEM1230 transmission electron microscope (TEM) at $30 \mathrm{kV}$.

\section{Cystic cavity assessment}

Spinal cord sections of each rat were stained with HE/Nissl for cavity assessment. One in every ten of the whole series of sections from each rat was selected for cavity area analyses. Cavities at the lesion/graft area were imaged at a $25 \times$ magnification and captured through a digital camera mounted on a microscope. The cavity volume (pixels) of these representative images was determined with Adobe Photoshop.

\section{Cell quantification}

To determine the percentage of positively stained cells from the in vitro experiments, one in every ten of the whole series of sections from each scaffold was selected. For each section, five random microscopic visual fields were observed. Thirty visual fields were evaluated for each experimental group, and all Hoechst 33342-labeled cells were counted. The percentage of cells that stained positively for nestin, $\beta$-tubulin 3 , or MAP 2 was calculated by counting the total number of nestin-, $\beta$-tubulin 3- or MAP 2-positive cells and dividing the result by the total number of Hoechst 33342-labeled cells.

For the in vivo percentage quantification of positive cells, the spinal cord lesion area of the longitudinal section was divided into three regions ( $\mathrm{R}, \mathrm{E}$ and $\mathrm{C}$ ) based on location (Figure $1 \mathrm{~F}$ ). One in every ten of the whole series of sections was arbitrarily selected from each rat, and six randomized areas in three regions (two areas per region) for each of the sections were selected under the microscope for every group. The percentage of nestin-, $\beta$-tubulin 3- or MAP 2-positive BrdU-labeled cells was obtained by counting the total number of nestin/ BrdU, $\beta$-tubulin 3/BrdU or MAP 2/BrdU double-positive cells and dividing the value by the total number of BrdU-positive cells.

\section{Statistical analysis}

All data are presented as the mean \pm SD. Statistical differences between two groups were analyzed using Student's $t$ test or the Mann-Whitney $U$ test. A comparison of the mean BBB scores in the AS+MS group before and after re-transection was performed using a paired $t$ test. Those shared among three or more groups were determined using one-way ANOVA and Bonferroni analyses. $P<0.05$ was considered a statistically significant difference.

\section{Results}

ASCs promote MSCs to differentiate into neuron-like cells in PLGA scaffolds

After $7 \mathrm{~d}$ of co-culture with ASCs, some MSCs exhibited a neuronal morphology. These cells acquired a neuronal shape with fusiform or multipolar cell bodies and obvious processes (Figure 2D). Antibodies against markers of neural precursor cells, nestin (Figure 2B), immature neuron marker $\beta$-tubulin 3 (Figure 2A), and mature neuron marker MAP 2 (Figure 2C) were used to test the differentiation of MSCs. The expression of nestin, $\beta$-tubulin 3 and MAP 2 was very low in the MSCs alone group and increased in the MSCs with ASCs co-culture group. A quantitative assessment indicated that the percentage of nestin-positive, $\beta$-tubulin 3-positive or MAP 2-positive cells was higher in the MSCs with ASCs co-culture group compared with the MSCs alone group at $7 \mathrm{~d}$ after culture in the scaffold in vitro $(P<0.01)$ (Figure $2 \mathrm{E})$. Interestingly, at $3 \mathrm{~d}$ co-culture with ASCs, a fraction of MSCs differentiated into nestin-positive cells, and the percentage of nestin-positive MSCs peaked $5 \mathrm{~d}$ after co-culture with ASCs and decreased on d $7(P<0.05)$ (Figure $2 \mathrm{~F})$. However, the percentage of $\beta$-tubulin 3 peaked on d 7 after co-culture with ASCs in vitro (Figure 2F). In prolonged cultures from 7 to $14 \mathrm{~d}$, the percentage of MAP 2-positive cells significantly increased $(P<0.05)$ (Figure $2 \mathrm{~F})$, which indicates that the neuronal differentiation was more robust as evidenced by the increased expression of MAP 2 (Figure 2F).

\section{Functional recovery}

To evaluate the locomotor functional improvements, the rats were evaluated using the BBB open-field walking scale before and after SCI. The BBB scores of the rats were 21 points preoperation, which changed to zero immediately after the operation in all five groups. In the AS+MS group, the BBB scores of the rats were significantly higher than the scores in the other groups at 4 weeks after the surgery and thereafter (Figure 3A). Over the course of 8 weeks, the mean hindlimb BBB score in the AS+MS group $(n=8)$ was $10.13 \pm 1.13$, and the scores in some individual rats reached 11 (Figure 3A). In contrast, the BBB scores were not higher than 3 in the SCI and ES groups (Figure 3A). To determine whether the improvement in locomotor function is related to regenerated nerve tissues, re-transection was performed in the middle of the lesion/graft site in the AS+MS group at 8 weeks after the first operation. As expected, the mean BBB scores decreased from $10.13 \pm 1.13$ to 0 (Figure $3 \mathrm{~A}$ ). To evaluate the coordination of the hindlimbs and the involvement of major joints, the inclined grid test was also performed. In the AS+MS group, coordination between forelimbs and hindlimbs was often observed (Figure 3B). In contrast, rats in the ES and SCI groups climbed the grid with their forelimbs, and the hindlimbs simply dragged along without a spontaneous placing reflex (Figure 3B).

\section{Electrophysiological testing}

Because the peak and width of evoked potentials (EP) may reflect the number of regenerated axons and the conduction velocity of the nerve, we measured the EP to further determine recovery in sensory and motor functions. At 2 weeks after cell transplantation, no sensory evoked potential (SEP) or motor evoked potential (MEP) could be evoked, even with consider- 

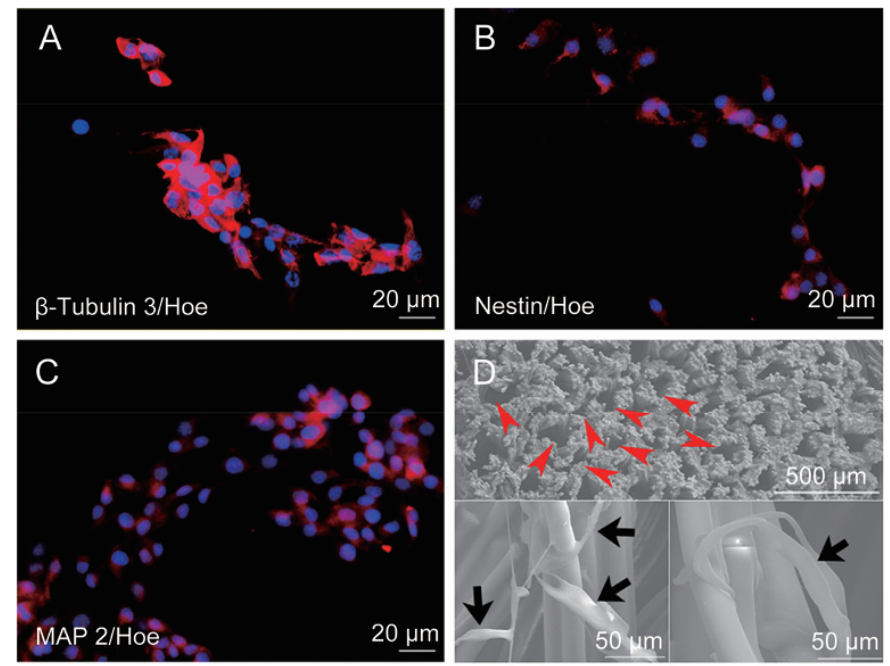

\section{$\mathrm{E}$}

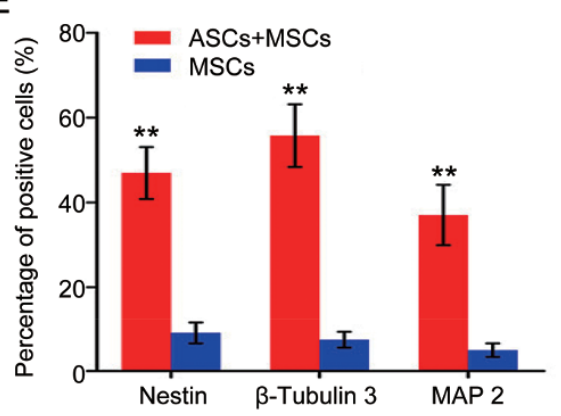

$\mathrm{F}$

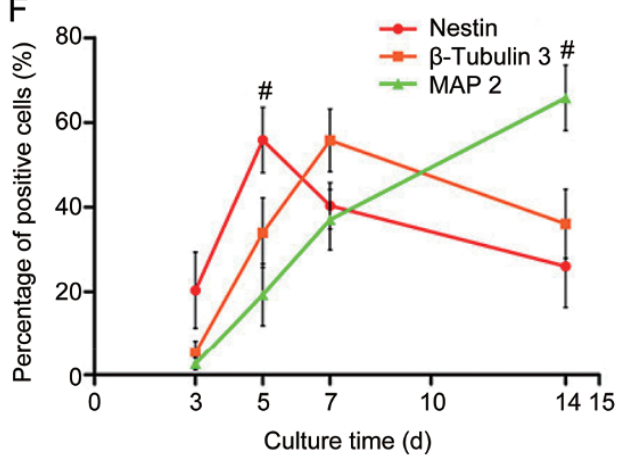

Figure 2. ASCs promote MSCs to differentiate into neuron-like cells in multiple-channel PLGA scaffolds in vitro. (A-C) At $7 \mathrm{~d}$ after co-culture with ASCs, Hoechst 33342-labeled MSCs differentiate into cells expressing markers of neural precursor cells, nestin (B), immature neuron marker $\beta$-tubulin 3 (A), and mature neuron marker MAP 2 (C). Red shows positively stained cells (arrows); blue shows Hoechst 33342-labeled MSC nuclei. (D) Cryo-SEM images showed the structure of micro-channels (red arrowhead) and the inner channels seeded with ASCs and MSCs (arrow). The cells attached to the scaffold and oriented along the direction of the fibers (arrow). (E) Positive cell percentage quantification showed that the percentage of nestin-positive, $\beta$-tubulin 3-positive and MAP 2-positive cells was significantly higher in the MSCs with ASCs co-culture group than in the MSCs alone group ( ${ }^{* *} P<0.01$ ). (F) Quantitative analyses of neuronal differentiation of Hoechst 33342-labeled MSCs at various points in time after co-culture with ASCs in the scaffold in vitro. The percentage of nestin-positive MSCs peaked $5 \mathrm{~d}$ after co-culture with ASCs and $\beta$-tubulin 3 on d 7 . In prolonged culture duration from 7 to $14 \mathrm{~d}$ the percentage of MAP 2-positive cells increased from $37.12 \% \pm 7.12 \%$ to $65.76 \% \pm 7.73 \%\left({ }^{\#} P<0.05\right.$, compared with $7 \mathrm{~d}$ after co-culture).

able electric stimulation, in all groups. At 4 weeks after the operation, only the AS+MS group exhibited some recovery of the SEP and MEP. Over the course of 8 weeks, the rats in the SCI and ES groups exhibited a negligible signal level of the MEP and SEP (Figure 4A). The latency in the MEP tests was the shortest and the amplitude was the highest in the AS+MS group; however, neither group returned to normal levels (Figure 4B). These results may indicate that the nerve regeneration at the lesion area in the AS+MS group bridged the local neural network to conduct signals from the supraspinal descending pathways, such as the corticospinal or rubrospinal pathway.

\section{Nerve regeneration}

In all groups, gross morphological changes within the lesion areas were examined at 4 and 8 weeks after injury. In the SCI group, the lesion area was occupied by fibrous and cystic tissues and formed scar-like tissues (Figure 5A, 5C). In the AS+MS group, tissues grew into the scaffold from two ends and bridged the rostral and caudal cord stumps in the middle of the scaffold at 8 weeks after the transplantation (Figure 5B, $5 C)$. In the empty scaffold group, tissues eventually infiltrated into the scaffold with a few scar-like tissues. However, the epicenter of the lesion/graft area remained empty 8 weeks after injury in the ES group (Figure 5C). NF staining confirmed that the regenerated tissues in the AS+MS group were composed of axons (Figure 5B).

\section{PLGA scaffolds impede cyst and scar formation}

Eight weeks post-operation, the area of the cystic cavity was measured at the lesion/graft area in all groups. In the AS+MS group, the grafts integrated best with the host tissue of the spinal cord by bridging the rostral and caudal stumps compared with the other four groups (Figure 5B). In both the AS and 
A

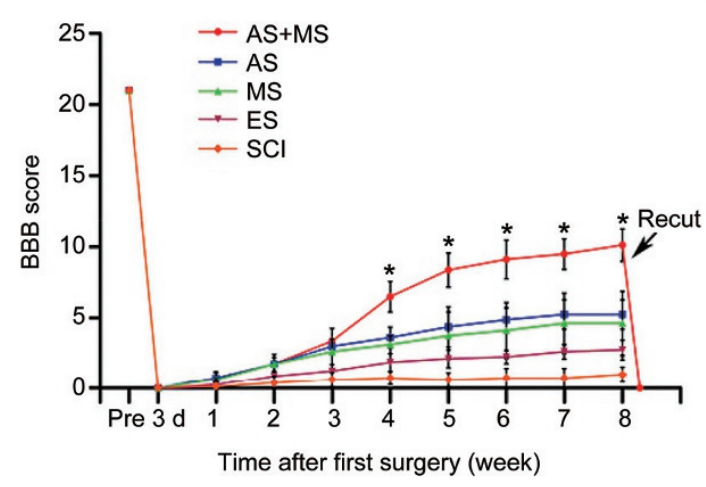

B

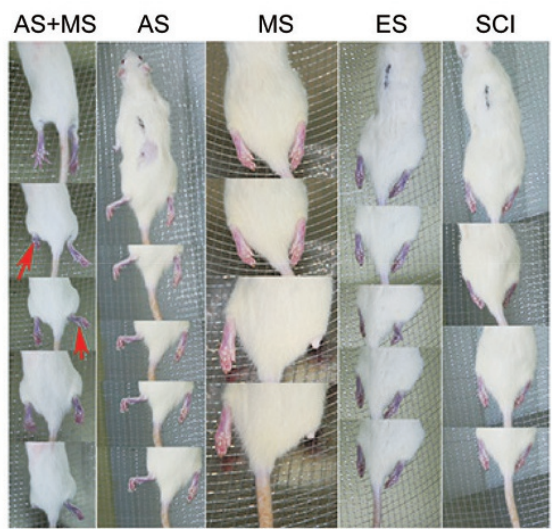

Figure 3. BBB locomotion assessment and grid climb test. (A) At 4 weeks after the surgery and thereafter, the AS+MS groups had significantly higher BBB scores than the other groups ( ${ }^{*} P<0.05, n=8$, one-way ANOVA). Re-transection in the middle of the lesion area in the AS+MS group abolished functional improvements when assessed $3 \mathrm{~d}$ later $(P<0.01, n=4$, paired $t$ test comparing before and after re-transection). (B) Representative images of rats on the inclined grid. The left panel in (B) showed rat in the AS+MS group properly stepped and placed its hindlimbs (red arrow) on the rungs and was capable of supporting its weight with the hindlimbs. The rats in the AS and MS groups showed slight movement of two or three joints and in the ES and $\mathrm{SCl}$ groups, rats hung with their forelimbs with their hindlimbs dragging behind.

A

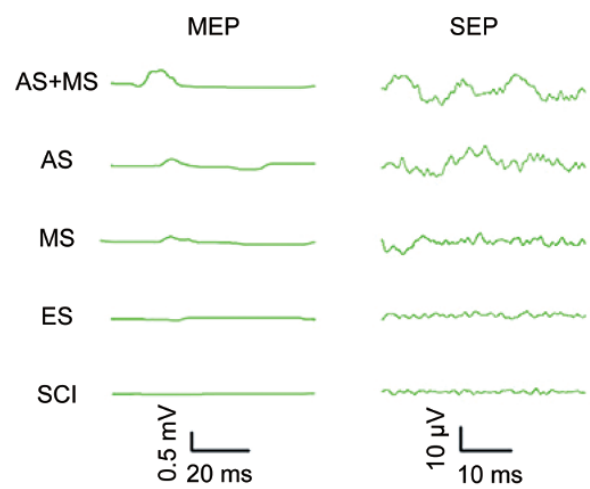

B

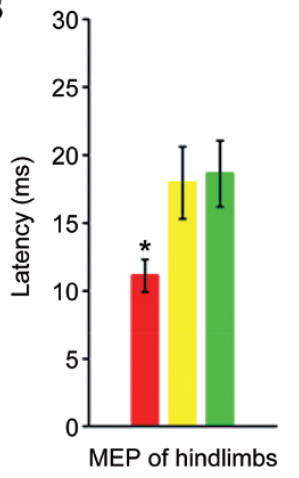

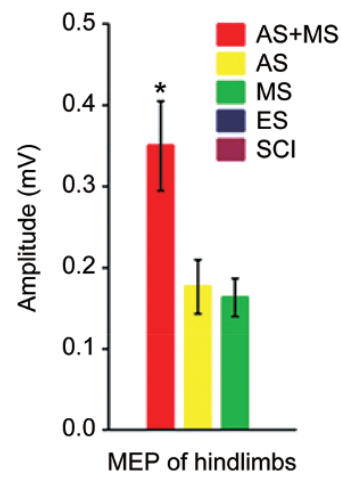

Figure 4. Electrophysiological analyses of sensory and motor functional restorations. (A) MEP and SEP graphs of all groups at 8 weeks after the operation. Note that only the AS+MS group exhibited stable wave forms. All rats in ES and SCl groups had no detectable signals. (B) Quantitative analyses of the latency and amplitude of MEP of all groups. The bar chart shows a significantly shorter latency (left panel) and larger amplitude (right panel) in the AS+MS group compared with other groups ( ${ }^{*} P<0.05$ vs AS or MS, $n=6$ ).

MS groups, the cavities were smaller than in the lesion control group $(P<0.05)$ (Figure 5D). The smallest cavity area was identified in the AS+MS group $(P<0.05)$ (Figure 5D). There was no significant difference between the AS and MS groups in the average size of the cystic cavity $(P>0.05)$ (Figure 5D).

\section{Survival, differentiation, and migration of implanted MSCs in vivo} The fate of BrdU-labeled MSCs in the injured spinal cord was assessed at 4 and 8 weeks after transplantation. At 4 weeks post injury, BrdU-labeled MSCs survived and were distributed in the injury/graft site or around the host-graft interface in the AS+MS and MS groups (Figure 6A). In the AS+MS group, some implanted MSCs differentiated into NPCs and immature neurons, which were nestin-positive or $\beta$-tubulin 3-positive. In addition, nestin and $\beta$-tubulin 3 double-positive (Figure $6 \mathrm{~B})$ and MAP 2-positive cells were also detected in the lesion/ graft area, which indicates the differentiation of progenitor cells into new neurons. However, few BrdU-labeled MSCs had differentiated into neuron-like cells in the MS group (Figure $7 \mathrm{~B}$ and $8 \mathrm{~A}$ ).

Eight weeks after SCI in the AS+MS group, the percentages of BrdU-labeled nestin-positive and $\beta$-tubulin 3-positive cells decreased from $23.92 \% \pm 2.59 \%$ and $25.97 \% \pm 3.24 \%$ to $18.75 \% \pm 3.11 \%$ and $21.63 \% \pm 2.8 \%$, respectively, and the percentages of the MAP 2 and BrdU double-positive cells increased from $19.5 \% \pm 2.75 \%$ to $24.5 \% \pm 2.75 \%$ (Figure $8 \mathrm{~B}$ ). The decline of nestin-positive and $\beta$-tubulin 3-positive cells at 8 weeks was likely a result of some NPCs and immature neurons differentiating into mature neurons and the programmed cell death of some immature neurons that failed to integrate into neural circuits. 

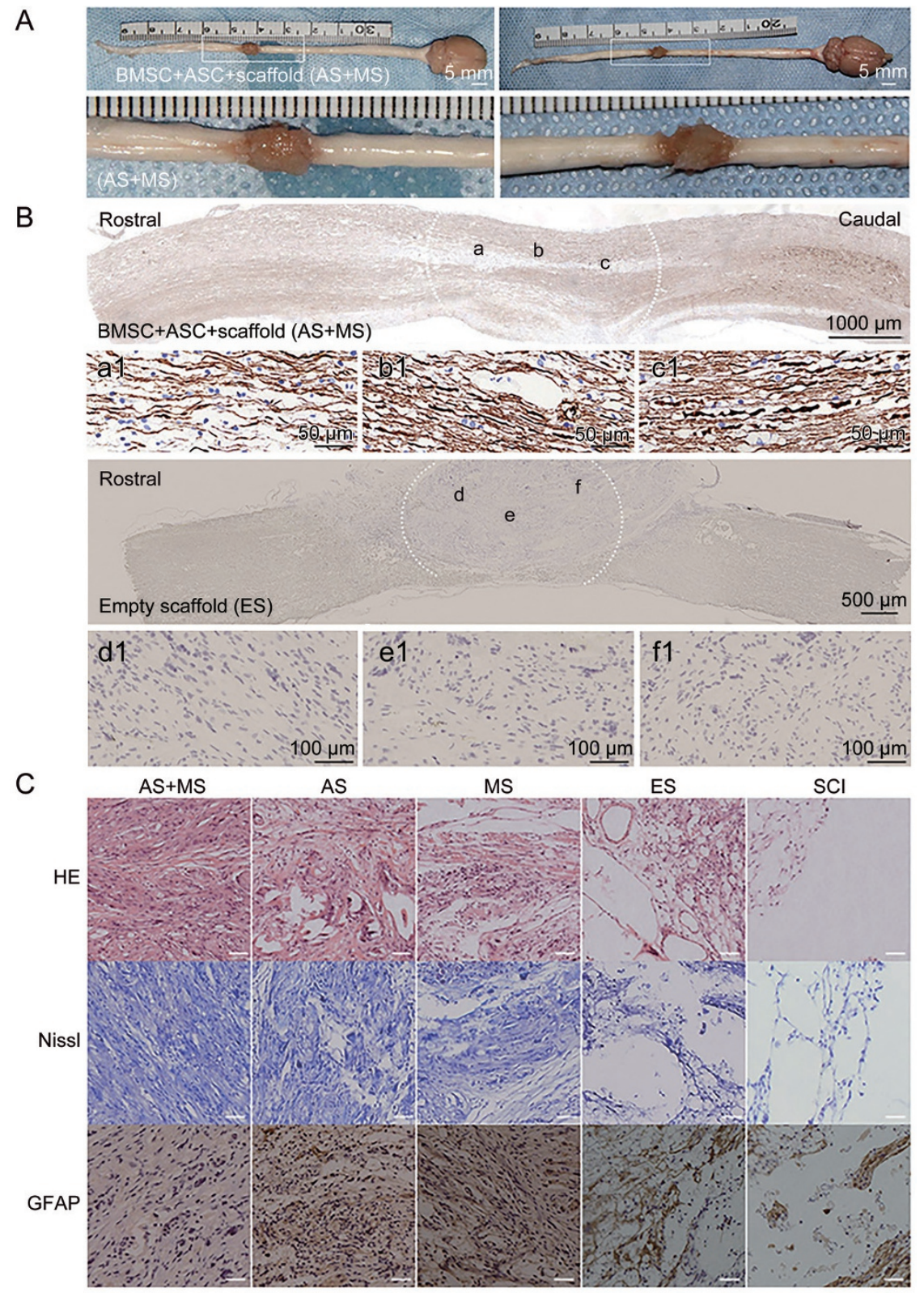

D

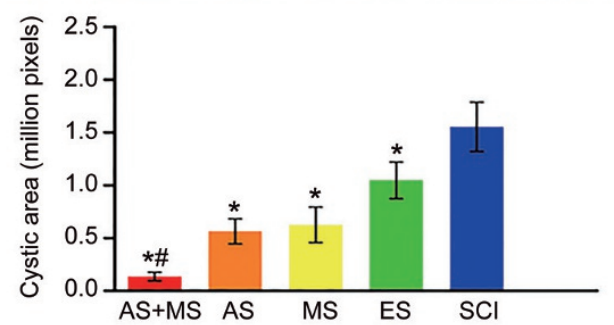

Figure 5. Nerve regeneration, cysts, and scar formation. (A) Dorsal view of whole spinal cords showing macroscopic repair of transected sites from AS+MS group (left panel) and ES group (right panel) at 8 weeks after the transplantation. Note that scaffolds with or without cells closely bridged the rostral and caudal stumps. (B) NF staining of regenerated nerve fibers in the AS+MS and ES groups at 8 weeks after the operation. Serial magnifications of the images at positions $\mathrm{a}, \mathrm{b}$, and $\mathrm{c}$ are shown as a1, b1, and c1. Both nerve fibers and neuronal cells were present in the lesion area in AS+MS group (top panel), but not in the ES (lower panel) or SCl (not shown) groups. (C) HE, Nissl staining and GFAP immunohistochemistry in the epicenter area in all groups. Note a large number of regenerated fibers with small cavity formation and a few GFAP positive cells in the AS+MS group. Except for some GFAP positive cells around the cavity, there were almost no tissue regeneration in the middle of the lesion area in the SCl group. (D) Statistical analysis of cystic cavity area among the 5 groups. Scaffold transplantation caused significantly smaller area of cystic cavity at the lesion site of spinal cord $\left({ }^{*} P<0.05\right.$, compared with the SCl group), especially in the AS+MS group ( ${ }^{*} P<0.05$, compared with other groups). The white dotted lines indicated the host-graft interface. Scale bars $=50 \mu \mathrm{m}$ in (C). 
A

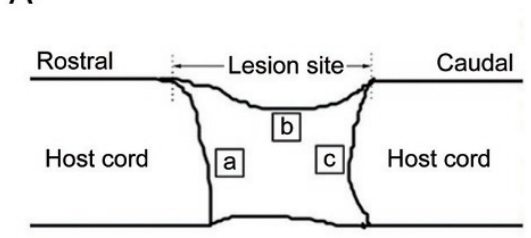

$(\mathrm{AS}+\mathrm{MS})$
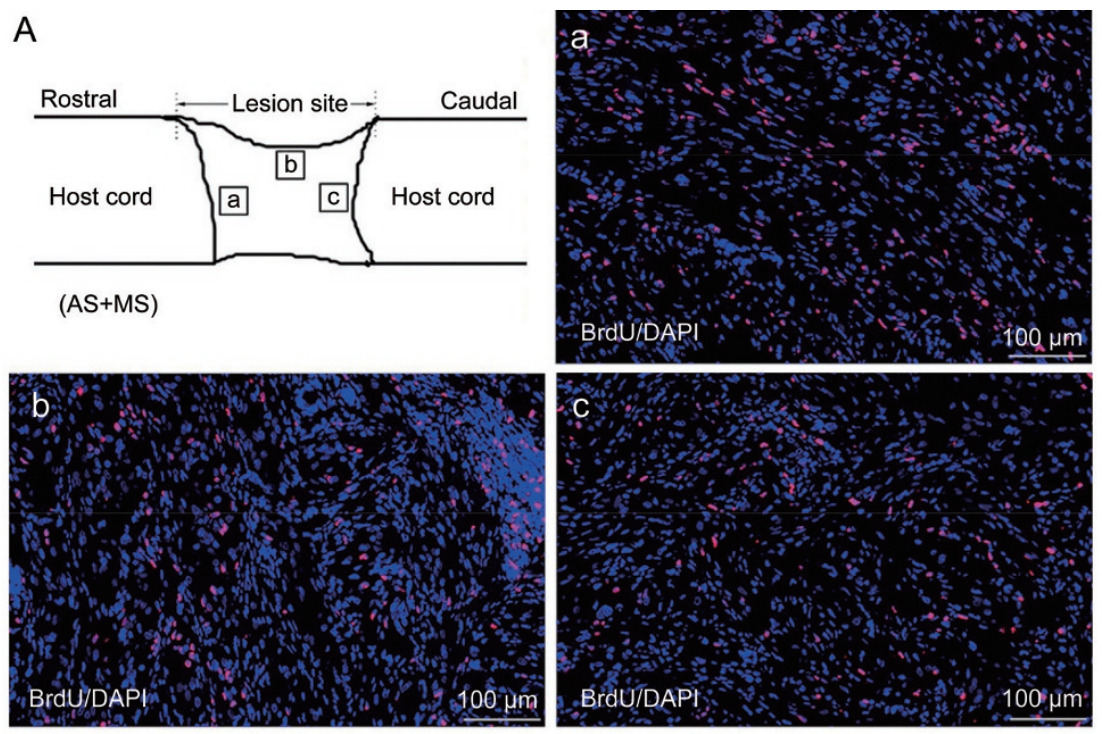

B

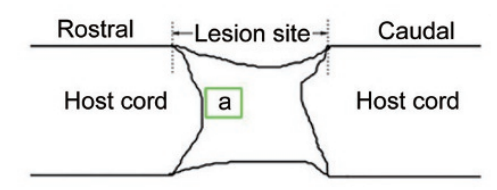

(AS+MS)

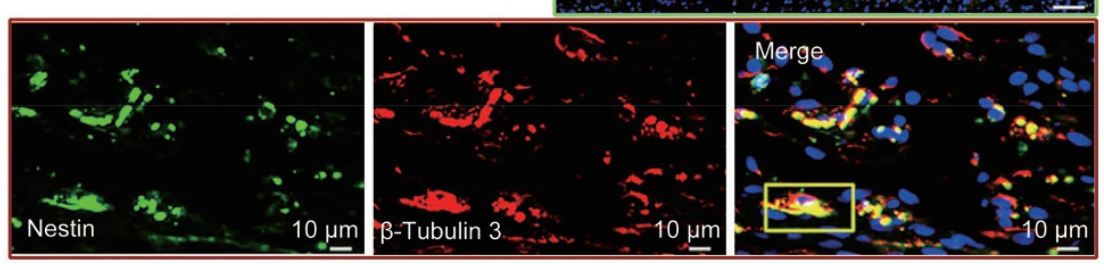

Figure 6. Survival, differentiation, and distribution of implanted MSCs at 4 weeks after the operation. DAPI (blue) was used to mark nuclei. (A) BrdUlabeled MSCs survived and were distributed in the lesion/graft site or around the host-graft interface in AS+MS and MS (not show) groups. (B) Nestin and $\beta$-tubulin 3 double-positive cells were observed in the lesion/graft site, demonstrating differentiation of progenitor cells into new neurons. Serial magnifications of the color-boxed area were shown.

Host neurons migrate into the lesion/graft site

Following transplantation into the spinal cord for 8 weeks, BrdU-labeled cells consistently filled the lesion/graft site. BrdU and MAP 2 immunostaining indicated that numerous BrdU and MAP 2 double-positive cells co-localized with host neurons (MAP 2-positive and BrdU-negative cells) (Figure 9) in the lesion/graft area in the AS+MS and AS groups. These BrdU-negative mature neurons migrated from the host spinal cord into the lesion area. Interestingly, BrdU-labeled MSCs were occasionally observed migrating into host tissue over short distances (Figure 9).

Myelination of axons and expression of neurotransmitters in the lesion area

A substantial number of regenerated fibers was observed in the lesion/graft site in the AS+MS group, and NF staining confirmed that these fibers were axons. SCs provide physi- cal support by ensheathing and myelinating axons, and we observed MBP-positive myelin sheath, confirmed via electron microscopy, in the AS+MS and AS groups (Figure 10A-10C). The myelination of axons contributes to the conduction velocity of the nerve, and the robust remyelination in the lesion/ graft corresponds to the shortened latency of the MEP in the AS+MS and AS groups (Figure 4B).

Importantly, in addition to expressing mature neuronal markers, sparse BrdU-labeled cells also expressed choline acetyltransferase (ChAT) (Figure 10D) in the injury area of the AS+MS group only.

\section{Discussion}

The adult mammalian CNS, unlike many other tissues, has a limited capacity to regenerate after traumatic injury. This inability of neurons to regenerate after SCI in the adult CNS leads to devastating sensory, motor, and autonomic impair- 
A

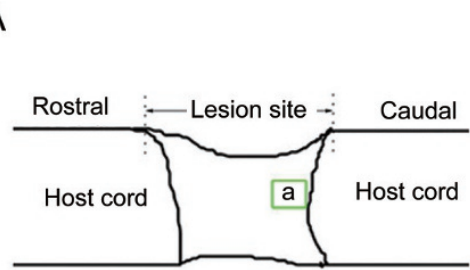

(AS+MS)
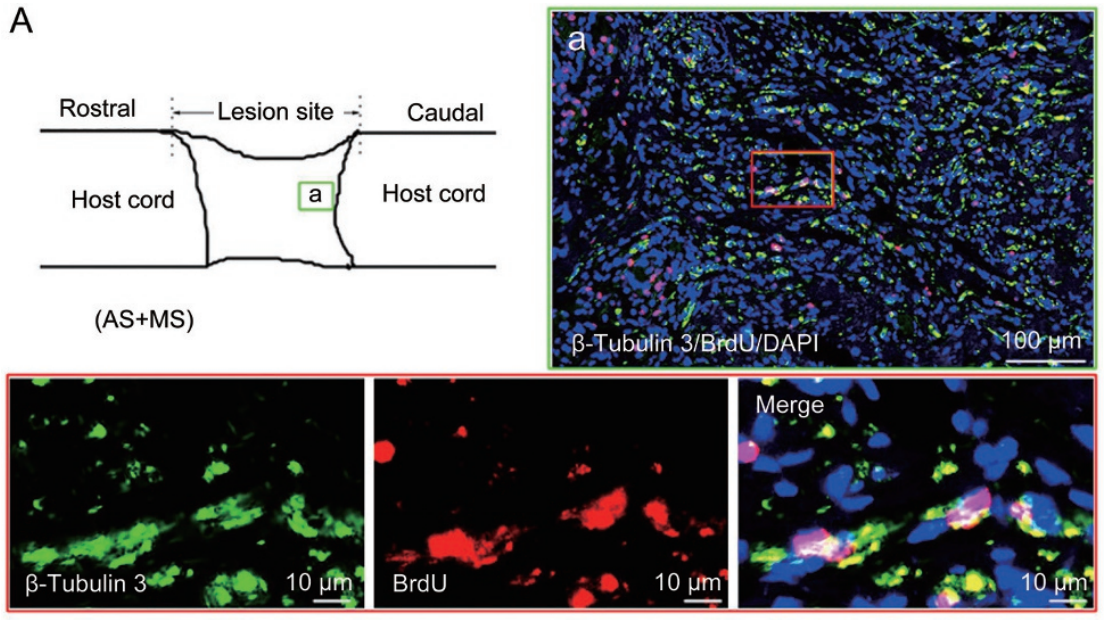

B

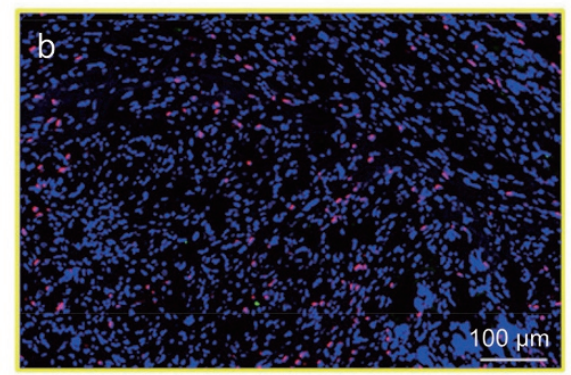

Figure 7. Comparison of neuronal differentiation of BrdU-labeled MSCs between AS+MS and MS groups at 4 weeks after the transplantation. DAPI (blue) was used to mark nuclei. Serial magnifications of the color-boxed area were shown. (A) Immunofluorescence staining of $\beta$-tubulin 3-and BrdU-positive cells in the lesion/graft area of the AS+MS group. Some $\beta$-tubulin 3- and BrdU-double-positive cells (arrow) were observed, indicative of neuronal differentiation. (B) Few BrdU-labeled MSCs expressed immature neurons marker $\beta$-tubulin 3 in the lesion/graft area in the MS group.

ments. Many therapeutic strategies have been developed to overcome the biological complications in the process of neurological recovery after SCI, and no single therapy will be sufficient to overcome all obstacles ${ }^{[46]}$. Here, we used a combinatorial strategy to promote axon regeneration and functional recovery after complete transection of the thoracic spinal cord in adult rats. This combined treatment not only permitted more neuronal differentiation of MSCs but also had several unique properties. The cells used in the current study were all primary cells without gene modification or transfection. These cells could be harvested from different sites in the patient's skeletal and neural tissues, such as the iliac crest and sciatic nerve. When used as grafts, these cells have the potential for clinical autologous transplantation, without the risk of severe immune rejection. Clinical investigations have indicated that the transplantation of autologous MSCs is feasible and safe $^{[47-50]}$. PLGA has been widely used as an artificial catheter, drug controlled-release carrier, and tissue engineering scaffold material for its mechanical properties and biodegradation. The multichannel polymer scaffold used in the current work mimics a suitable three-dimensional environment for tissue growth and helps grafted neuron-like cells extend processes from their cell bodies as a function of the micro-channels inside the scaffold. The scaffold also minimizes the reactive state of contaminating glial cells and impedes cyst and scar formation. In the current study, PLGA scaffolds effectively bridged the lesion gap in the SCI rats.

We employed a completely transected SCI model for two reasons. First, the complete transection model destroys the entire neural network at and around the spinal cord, which could distinguish between bona fide regeneration and other forms of regenerative growth and exclude self-recovery, reported in previous hemi-section and contusion SCI mod$\mathrm{els}^{[51-53]}$. Second, the complete transection model is a faithful model of spinal cord injury for translational cell transplantation $^{[54]}$. In this study, the BBB score was 0 immediately after the operation for all completely transected rats, and over the course of 8 weeks, the BBB scores in the SCI group were not greater than 1.5 .

Following the complete transection and removal of a 3-mm thoracic spinal cord segment, a permanent gap was formed at the lesion area. Effectively bridging the rostral and caudal stumps has been one of the top priorities for spinal cord

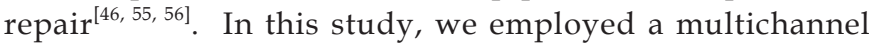
PLGA scaffold seeded with ASCs and MSCs to bridge the lesion gap after complete transection of the thoracic spinal cord in adult rats. The scaffolds impeded cyst formation and promoted tissue regeneration in the lesion/graft site. The rats with transplanted scaffolds exhibited a higher BBB score than rats in the SCI group. Furthermore, immunostaining for 
A
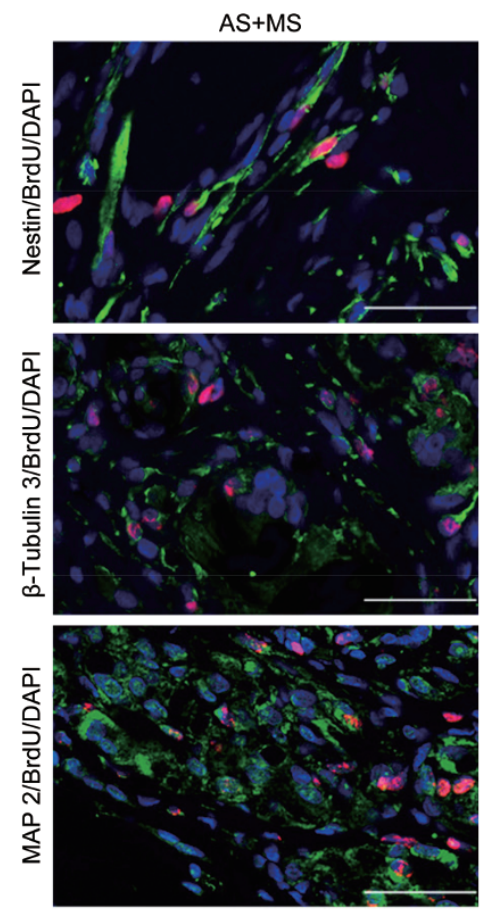

B

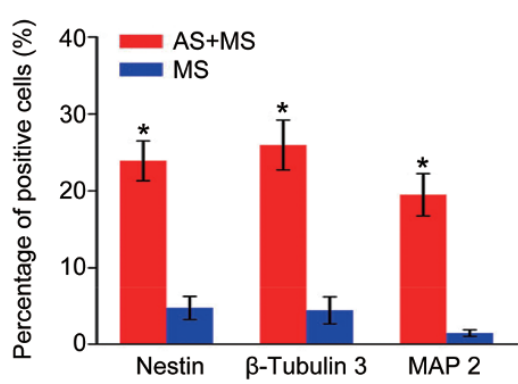

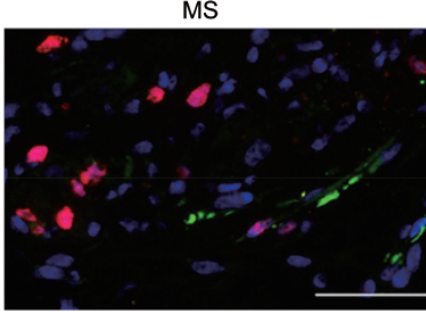
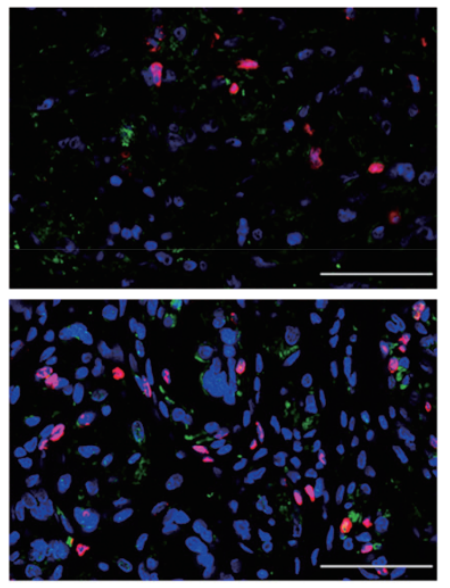

C

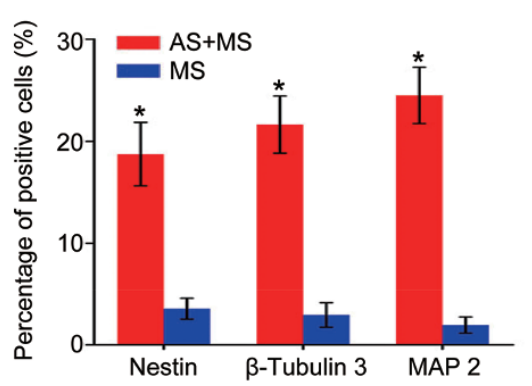

Figure 8. Survival and differentiation of implanted MSCs at 8 weeks after the operation. (A) Immunofluorescence staining showed many BrdU-labeled nestin-, $\beta$-tubulin 3-, and MAP 2-expressing neural lineage cells in the epicenter of the lesion/graft area in the AS+MS group. In contrast, few BrdUlabeled MSCs expressed those neuronal markers in the MS group. DAPI (blue) was used to mark nuclei. (B) and (C) Quantitative analyses of neuronal differentiation of BrdU-labeled MSCs in the lesion/graft site at 4 weeks $(B)$ and 8 weeks $(C)$ after the transplantation $\left({ }^{*} P<0.05\right.$, compared with the MS group). Scale bars $=50 \mu \mathrm{m}$ in (A).

GFAP in the lesion area indicated that the groups that received the scaffold seeded with cells or scaffold alone exhibited a smaller population of GFAP-positive astrocytes at the lesion/ graft site than the SCI group. These findings suggest that the scaffold played an important role in functional recovery.

SCs are one of the most commonly used cell types for repairing the injured spinal cord and contribute to nerve regeneration in both the PNS and CNS by secreting a substantial variety of neurotrophic factors ${ }^{[25-27]}$. Compared with SCs, activated SCs enhance axonal regeneration in SCI models and significantly promote functional recovery by expressing various neurotrophic factors and cell adhesion molecules and supply the extracellular matrix ${ }^{[33-37]}$. In this study, after coculture in vitro for $7 \mathrm{~d}$, ASCs promoted the differentiation of MSCs into neuron-like cells that express immature and mature neuron markers, such as $\beta$-tubulin 3 and MAP 2. The percent- age of MSC-derived neuron-like cells in the ASCs and MSCs co-culture group was significantly higher than the MSCs alone group. Eight weeks post-transplantation in vivo, $24.5 \% \pm 2.75 \%$ of BrdU-labeled MSCs differentiated into neuron-like cells that expressed MAP 2 in the AS+MS group. In contrast, only $1.93 \% \pm 0.78 \%$ of BrdU-labeled MSCs differentiated into neuron-like cells in the MS group. Interestingly, endogenous neurons (MAP 2-positive and BrdU-negative cells) were also detected in the lesion/graft site in both the AS+MS and AS groups in contrast to the MS group. We suggest that ASCs effectively enhance the efficacy of neuronal differentiation of $\operatorname{MSCs}^{[38]}$.

NSCs have been suggested to hold the key to neural regeneration and functional recovery in CNS injury ${ }^{[11,12,16]}$. Lu et $a l^{[16]}$ reported that the transplantation of neural stem cells established a functional bridge across completely transected 


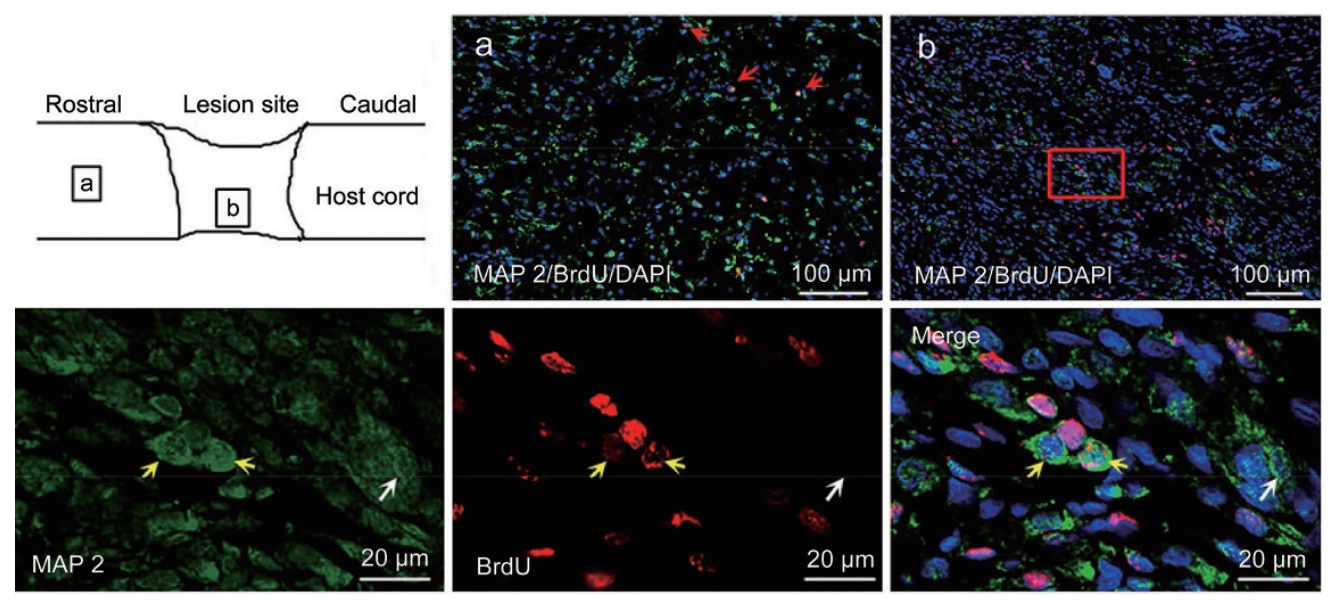

Figure 9. MSC-derived neuron-like cells co-localized with host neurons in the lesion area at 8 weeks after the transplantation. (a) Immunographs showed transplanted BrdU-labeled MSCs (red arrow) migrating into host tissue over short distances. (b) Immunographs showed numerous BrdU and MAP 2 double-labeled cells (yellow arrow) co-localized with host neurons (MAP 2-positive and BrdU-negative cells) (white arrow). DAPI (blue) was used to mark nuclei. Serial magnifications of the color-boxed area are shown.

spinal cords in rats. MSCs have been reported to be capable of differentiating into neuron-like cells that express neuronal markers in vitro and in vivo ${ }^{[17,22,57]}$. The abundance of regenerated tissues, confirmed to be nerve fibers by NF staining in the AS+MS group, was associated with the differentiation of grafted MSCs into neuron-like cells. These fibers bridged the rostral and caudal stumps at the injury epicenter. In addition to expressing mature neuronal markers, sparse MSC-derived neuron-like cells expressed ChAT in the injured areas of the AS+MS group only. These findings demonstrated the most significant motor functional recovery occurred in the AS+MS group compared with the other groups. No definitive corticospinal tract axons were detected in all groups; however, the partial restoration of the latencies and amplitudes of the SEP and MEP in the AS+MS group indicated that the number of regenerated axons and the conduction velocity of the nerve could be recovered through our combinatorial strategy. The myelination of new regenerated axons in the lesion area, confirmed via electron microscopic analysis and MBP immunohistochemistry, also contributed to the recovery of the behavioral and electrophysiological functions in the AS+MS group.

Stem cell transplantation is promising; however, this technique is currently suboptimal. Different procedures have been reported, including intravenous, intramedullary and intradural transplantations ${ }^{[38,58-60]}$. Following systemic and parenchymal transplantation, the limited number and viability of stem cells in situ and pulmonary passage impede the effectiveness of this technique ${ }^{[61,62]}$. Oraee-Yazdani et al reported a co-transplantation of autologous bone marrow mesenchymal stem cells and Schwann cells through cerebral spinal fluid (CSF) for the treatment of patients with chronic spinal cord injury ${ }^{[58]}$. During follow-up, which lasted an average of 30 months, no evidence of neoplastic tissue overgrowth was identified via magnetic resonance imaging. An improvement in the neurological status was observed only in one patient, and no motor score improvement was observed among the patients. However, a recently published article demonstrated that transplantation of human neural stem cells (hNSCs) directly into the site of injury did not cause significant functional improvement, whereas distal injection achieved a statistically significant difference ${ }^{[59]}$. The authors hypothesized that the transplanted hNSCs secrete numerous cytokines and growth factors to suppress the local immune system, inhibit further scar formation, and promote apoptosis ${ }^{[59]}$. Furthermore, the trophic effects of the cells may be more effective while they are freely mobile in the cerebrospinal fluid after lumbar puncture; however, they have a decreased ability to survive and provide humoral support when injected into the area of an established glial scar in this chronic model of SCI. In the current work, the 3D scaffolds were used to create a platform with microarchitecture that provides the appropriate microenvironment to promote the survival and distribution of transplanted cells. Eight weeks after the operation, immunofluorescence staining indicated that many BrdU-labeled cells survived and were distributed in the lesion/graft area (Figure 8).

Kim et al reported a comparative study between intralesional injection and scaffold-based transplantation ${ }^{[63]}$. The results indicated better cell engraftment and neuroprotective effects in the scaffold groups than the intralesional injection group. However, studies have shown that only a small proportion of MSCs differentiate into neural cells in vitro, and the implantation of MSCs alone in vivo does not improve functional recovery ${ }^{[23]}$. In Kim et al's research, the mean numbers of engrafted MSCs that exhibited neuronal differentiation were $13.37 \pm 1.46$ in the PLGA scaffold group and $14.53 \pm 0.6$ in the chitosan scaffold group, which were both higher than the mean of $11.92 \pm 1.69$ in the intralesional injection group ${ }^{[63]}$. In the current study, 8 weeks after SCI, the percentage of BrdUlabeled tubulin 3-positive cells was $25.97 \% \pm 3.24 \%$ in the AS+MS group. This greater level of neuronal differentiation 


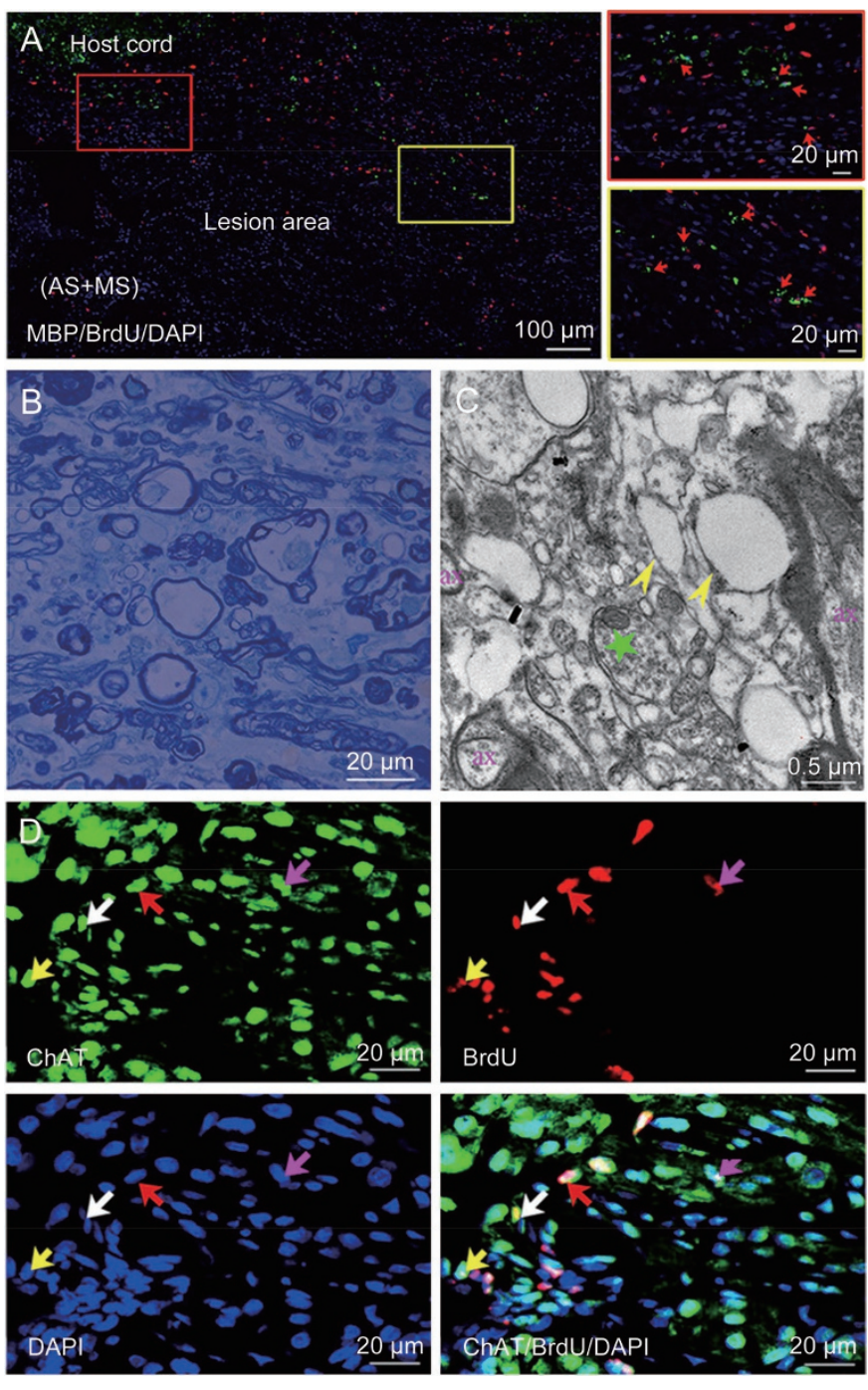

Figure 10. Expression of MBP and neurotransmitters in the lesion/graft site. (A) Immunographs of myelin basic protein (MBP)-positive cells in the regenerating nerve tissues of the AS+MS group at 8 weeks after cell transplantation. Magnifications of framed regions are shown in the top right panel. In the epicenter of lesion/graft area, some MBP- and BrdUdouble-positive cells were observed (arrows), indicative of newly myelination of axons. (B) Toluidine blue staining of semi-thin cross-section for a sample from the AS+MS group, showed numerous cells and myelination of regenerated nerve fibers in the middle of the lesion/graft area. (C) Under TEM, a varying number of myelinated axons (ax) and vacuoles (arrowhead) were observed in the lesion area in AS+MS group. The star represents the axoplasm, in which the neurofilaments and vesicles were found. Occasional BrdU-labeled cells expressed ChAT (arrow in D).

is attributable to neurotrophic factors, including glial cell linederived neurotrophic factor (GDNF) mRNA and brain-derived neurotrophic factor (BDNF) mRNA, expressed in activated Schwann cells ${ }^{[33-35]}$.

The significant recovery in function identified in the AS+MS group may also be a result of the excellent growth-promoting and neural-protecting microenvironment of ASC- and MSCseeded scaffolds in the lesion area. The ASCs secreted various neurotrophic factors and promoted the survival and differentiation of the grafted MSCs. Eight weeks post-transplantation, nestin and $\beta$-tubulin 3 double-positive cells and MAP 2-positive cells were detected in the lesion side in the AS+MS group, which indicates the survival and differentiation of progenitor cells into new neurons. The multichannel scaffolds provided structure that supported cell adhesion and reduced scar and cyst formation. This facilitated cell survival and axonal regeneration. In general, it is accepted that combined treatment may be more effective ${ }^{[64-66]}$.

In summary, following co-transplantation, MSCs were induced to differentiate into neuron-like cells in the presence of ASCs and promoted axonal regrowth and functional recovery after rat spinal cord transection. Local neural networks were created through ASC-induced and MSC-derived neuron-like cells that made contacts with host neurons. This donor-derived restoration of neural connectivity was verified by retransection in the middle of the lesion/graft site at 8 weeks after the first operation. The BBB score of the rats that received retransection decreased to the complete SCI level.

In conclusion, the multichannel PLGA scaffold effectively bridged the lesion gap in completely transected SCI rats, and the co-implantation strategy promoted MSC survival and differentiation into neuron-like cells, which led to enhanced regeneration of axons and functional recovery. This study indicates the potential therapeutic effect of a combinatorial strategy to address complex neurological maladies.

\section{Acknowledgements}

This work was supported by the National Natural Science Foundation of China (NSFC 81272001).

\section{Author contribution}

Xiao-feng LIAN, Jian-guang XU, and Er-zhu YANG designed the experiments; Er-zhu YANG, Guo-wang ZHANG, and Liang-liang CAO performed the research; Shuai CHEN and Hua WANG constructed the model; Bo LIANG and Xiaofeng LIAN analyzed the data; Er-zhu YANG and Guo-wang ZHANG wrote the manuscript; Xiao-feng LIAN and Jianguang XU reviewed and edited the manuscript.

\section{References}

1 Bradbury EJ, Moon LD, Popat RJ, King VR, Bennett GS, Patel PN, et al. Chondroitinase $\mathrm{ABC}$ promotes functional recovery after spinal cord injury. Nature 2002; 416 : 636-40.

2 Silver J, Miller JH. Regeneration beyond the glial scar. Nat Rev Neurosci 2004; 5: 146-56.

3 Okada S, Nakamura M, Katoh H, Miyao T, Shimazaki T, Ishii K, et al. Conditional ablation of Stat3 or Socs3 discloses a dual role for reactive astrocytes after spinal cord injury. Nat Med 2006; 12: 82934.

4 Fawcett JW. Overcoming inhibition in the damaged spinal cord. J Neurotrauma 2006; 23: 371-83.

5 Sekhon LHS, Fehlings MG. Epidemiology, demographics, and pathophysiology of acute spinal cord injury. Spine 2001; 26: S2-S12.

6 Hagg T, Oudega M. Degenerative and spontaneous regenerative processes after spinal cord injury. J Neurotrauma 2006; 23: 264-80. 
7 Rowland JW, Hawryluk GWJ, Kwon B, Fehlings MG. Current status of acute spinal cord injury pathophysiology and emerging therapies: promise on the horizon. Neurosurg Focus 2008; 25: E2.

8 Bradbury EJ, McMahon SB. Opinion - Spinal cord repair strategies: why do they work? Nat Rev Neurosci 2006; 7: 644-53.

9 Nomura $\mathrm{H}$, Tator $\mathrm{CH}$, Shoichet MS. Bioengineered strategies for spinal cord repair. J Neurotrauma 2006; 23: 496-507.

10 Thuret S, Moon LDF, Gage FH. Therapeutic interventions for spinal cord injury. Nat Rev Neurosci 2006; 7: 628-43.

11 McDonald JW, Liu XZ, Qu Y, Liu S, Mickey SK, Turetsky D, et al. Transplanted embryonic stem cells survive, differentiate and promote recovery in injured rat spinal cord. Nat Med 1999; 5: 1410-2.

12 Park KI, Liu S, Flax JD, Nissim S, Stieg PE, Snyder EY. Transplantation of neural progenitor and stem cells: developmental insights may suggest new therapies for spinal cord and other CNS dysfunction. J Neurotrauma 1999; 16: 675-87.

13 Keirstead HS, Nistor G, Bernal G, Totoiu M, Cloutier F, Sharp K, et al. Human embryonic stem cell-derived oligodendrocyte progenitor cell transplants remyelinate and restore locomotion after spinal cord injury. J Neurosci 2005; 25: 4694-705.

14 Cummings BJ, Uchida N, Tamaki SJ, Salazar DL, Hooshmand M, Summers R, et al. Human neural stem cells differentiate and promote locomotor recovery in spinal cord-injured mice. Proc Natl Acad Sci U S A 2005; 102: 14069-74.

15 Barnabe-Heider F, Frisen J. Stem cells for spinal cord repair. Cell Stem Cell 2008; 3: 16-24.

16 Lu P, Wang YZ, Graham L, McHale K, Gao MY, Wu D, et al. Longdistance growth and connectivity of neural stem cells after severe spinal cord injury. Cell 2012; 150: 1264-73.

17 Woodbury D, Schwarz EJ, Prockop DJ, Black IB. Adult rat and human bone marrow stromal cells differentiate into neurons. J Neurosci Res 2000; 61: 364-70.

18 Black IB, Woodbury D. Adult rat and human bone marrow stromal stem cells differentiate into neurons. Blood Cells Mol Dis 2001; 27: 632-6.

19 Chopp M, Zhang XH, Li Y, Wang L, Chen JL, Lu DY, et al. Spinal cord injury in rat: treatment with bone marrow stromal cell transplantation. Neuroreport 2000; 11: 3001-5.

20 Ankeny DP, McTigue DM, Jakeman LB. Bone marrow transplants provide tissue protection and directional guidance for axons after contusive spinal cord injury in rats. Exp Neurol 2004; 190: 17-31.

21 Torres-Espin A, Redondo-Castro E, Hernandez J, Navarro X. Bone marrow mesenchymal stromal cells and olfactory ensheathing cells transplantation after spinal cord injury - a morphological and functional comparison in rats. Eur J Neurosci 2014; 39: 1704-17.

22 Sanchez-Ramos J, Song S, Cardozo-Pelaez F, Hazzi C, Stedeford T, Willing $A$, et al. Adult bone marrow stromal cells differentiate into neural cells in vitro. Exp Neurol 2000; 164: 247-56.

23 Brock JH, Graham L, Staufenberg E, Collyer E, Koffler J, Tuszynski MH. Bone marrow stromal cell intraspinal transplants fail to improve motor outcomes in a severe model of spinal cord injury. J Neurotrauma 2016; 33: 1103-14.

24 Hall S. Nerve repair: a neurobiologist's view. J Hand Surg Br 2001; 26: 129-36.

25 Xu XM, Guenard V, Kleitman N, Bunge MB. Axonal regeneration into Schwann cell-seeded guidance channels grafted into transected adult rat spinal cord. J Comp Neurol 1995; 351: 145-60.

26 Neuberger TJ, De Vries GH. Distribution of fibroblast growth factor in cultured dorsal root ganglion neurons and Schwann cells. I. Localization during maturation in vitro. J Neurocytol 1993; 22: 436-48.

27 Acheson A, Barker PA, Alderson RF, Miller FD, Murphy RA. Detection of brain-derived neurotrophic factor-like activity in fibroblasts and Schwann cells: inhibition by antibodies to NGF. Neuron 1991; 7 : 265-75.

28 Takami T, Oudega M, Bates ML, Wood PM, Kleitman N, Bunge MB. Schwann cell but not olfactory ensheathing glia transplants improve hindlimb locomotor performance in the moderately contused adult rat thoracic spinal cord. J Neurosci 2002; 22: 6670-81.

29 Oudega M, Xu XM. Schwann cell transplantation for repair of the adult spinal cord. J Neurotrauma 2006; 23: 453-67.

30 Torigoe K, Tanaka HF, Takahashi A, Awaya A, Hashimoto K. Basic behavior of migratory Schwann cells in peripheral nerve regeneration. Exp Neurol 1996; 137: 301-8.

31 Chernousov MA, Carey DJ. Schwann cell extracellular matrix molecules and their receptors. Histol Histopathol 2000; 15: 593601.

32 Zhang Y, Roslan R, Lang D, Schachner M, Lieberman AR, Anderson PN. Expression of CHL1 and L1 by neurons and glia following sciatic nerve and dorsal root injury. Mol Cell Neurosci 2000; 16: 71-86.

33 Hammarberg H, Piehl F, Cullheim S, Fjell J, Hokfelt T, Fried K. GDNF mRNA in Schwann cells and DRG satellite cells after chronic sciatic nerve injury. Neuroreport 1996; 7: 857-60.

34 Meyer M, Matsuoka I, Wetmore C, Olson L, Thoenen H. Enhanced synthesis of brain-derived neurotrophic factor in the lesioned peripheral nerve: different mechanisms are responsible for the regulation of BDNF and NGF mRNA. J Cell Biol 1992; 119: 45-54.

35 Hoke A, Cheng C, Zochodne DW. Expression of glial cell line-derived neurotrophic factor family of growth factors in peripheral nerve injury in rats. Neuroreport 2000; 11: 1651-4.

36 Rasouli A, Bhatia N, Suryadevara S, Cahill K, Gupta R. Transplantation of preconditioned schwann cells in peripheral nerve grafts after contusion in the adult spinal cord. Improvement of recovery in a rat model. J Bone Joint Surg Am 2006; 88: 2400-10.

37 Dinh P, Bhatia N, Rasouli A, Suryadevara S, Cahill K, Gupta R. Transplantation of preconditioned Schwann cells following hemisection spinal cord injury. Spine (Phila Pa 1976) 2007; 32: 943-9.

38 Ban DX, Ning GZ, Feng SQ, Wang Y, Zhou XH, Liu Y, et al. Combination of activated Schwann cells with bone mesenchymal stem cells: the best cell strategy for repair after spinal cord injury in rats. Regen Med 2011; 6: 707-20.

39 Zhang YQ, He LM, Xing B, Zeng X, Zeng CG, Zhang W, et al. Neurotrophin-3 gene-modified Schwann cells promote TrkC gene-modified mesenchymal stem cells to differentiate into neuron-like cells in poly(lactic-acid-co-glycolic acid) multiple-channel conduit. Cells Tissues Organs 2012; 195: 313-22.

40 Schwab JM, Brechtel K, Mueller CA, Failli V, Kaps HP, Tuli SK, et al. Experimental strategies to promote spinal cord regeneration - an integrative perspective. Prog Neurobiol 2006; 78: 91-116.

41 Bunge MB. Novel combination strategies to repair the injured mammalian spinal cord. J Spinal Cord Med 2008; 31: 262-9.

42 Yuan JD, Nie WB, Fu Q, Lian XF, Hou TS, Tan ZQ. Novel three-dimensional nerve tissue engineering scaffolds and its biocompatibility with Schwann cells. Chin J Traumatol 2009; 12: 133-7.

43 Keilhoff G, Fansa H, Schneider W, Wolf G. In vivo predegeneration of peripheral nerves: an effective technique to obtain activated Schwann cells for nerve conduits. J Neurosci Methods 1999; 89: 17-24.

44 Basso DM, Beattie MS, Bresnahan JC. A sensitive and reliable locomotor rating scale for open field testing in rats. J Neurotrauma 1995; 12: 1-21.

45 Ramon-Cueto A, Cordero MI, Santos-Benito FF, Avila J. Functional recovery of paraplegic rats and motor axon regeneration in their spinal cords by olfactory ensheathing glia. Neuron 2000; 25: 425-35. 
46 Teng YD, Lavik EB, Qu X, Park KI, Ourednik J, Zurakowski D, et al. Functional recovery following traumatic spinal cord injury mediated by a unique polymer scaffold seeded with neural stem cells. Proc Natl Acad Sci U S A 2002; 99: 3024-9.

47 Yazdani SO, Hafizi M, Zali AR, Atashi A, Ashrafi F, Seddighi AS, et al. Safety and possible outcome assessment of autologous Schwann cell and bone marrow mesenchymal stromal cell co-transplantation for treatment of patients with chronic spinal cord injury. Cytotherapy 2013; 15: 782-91.

48 Satti HS, Waheed A, Ahmed P, Ahmed K, Akram Z, Aziz T, et al. Autologous mesenchymal stromal cell transplantation for spinal cord injury: a phase I pilot study. Cytotherapy 2016; 18: 518-22.

49 Oh SK, Choi KH, Yoo JY, Kim DY, Kim SJ, Jeon SR. A phase III clinical trial showing limited efficacy of autologous mesenchymal stem cell therapy for spinal cord injury. Neurosurgery 2016; 78: 436-47.

50 Kakabadze Z, Kipshidze N, Mardaleishvili K, Chutkerashvili G, Chelishvili I, Harders A, et al. Phase 1 trial of autologous bone marrow stem cell transplantation in patients with spinal cord injury. Stem Cells Int 2016; 2016: 6768274.

51 Vinit S, Kastner A. Descending bulbospinal pathways and recovery of respiratory motor function following spinal cord injury. Respir Physiol Neurobiol 2009; 169: 115-22.

52 Alluin O, Karimi-Abdolrezaee S, Delivet-Mongrain $\mathrm{H}$, Leblond $\mathrm{H}$, Fehlings MG, Rossignol S. Kinematic study of locomotor recovery after spinal cord clip compression injury in rats. J Neurotrauma 2011; 28: 1963-81.

53 Steward 0, Willenberg R. Rodent spinal cord injury models for studies of axon regeneration. Exp Neurol 2017; 287: 374-83.

54 Lukovic D, Moreno-Manzano V, Lopez-Mocholi E, Rodriguez-Jimenez FJ, Jendelova P, Sykova E, et al. Complete rat spinal cord transection as a faithful model of spinal cord injury for translational cell transplantation. Sci Rep 2015; 5: 9640.

55 Wang JM, Zeng YS, Wu JL, Li Y, Teng YD. Cograft of neural stem cells and Schwann cells overexpressing TrkC and neurotrophin-3 respectively after rat spinal cord transection. Biomaterials 2011; 32 : 7454-68.

56 Kang KN, Kim da Y, Yoon SM, Lee JY, Lee BN, Kwon JS, et al. Tissue engineered regeneration of completely transected spinal cord using human mesenchymal stem cells. Biomaterials 2012; 33: 4828-35.

57 Hofstetter CP, Schwarz EJ, Hess D, Widenfalk J, El Manira A, Prockop $D J$, et al. Marrow stromal cells form guiding strands in the injured spinal cord and promote recovery. Proc Natl Acad Sci U S A 2002; 99 : 2199-204.

58 Oraee-Yazdani S, Hafizi M, Atashi A, Ashrafi F, Seddighi AS, Hashemi $\mathrm{SM}$, et al. Co-transplantation of autologous bone marrow mesenchymal stem cells and Schwann cells through cerebral spinal fluid for the treatment of patients with chronic spinal cord injury: safety and possible outcome. Spinal Cord 2016; 5X: 102-9.

59 Cheng I, Githens M, Smith RL, Johnston TR, Park DY, Stauff MP, et al. Local versus distal transplantation of human neural stem cells following chronic spinal cord injury. Spine J 2016; 16: 764-9.

60 Morita T, Sasaki M, Kataoka-Sasaki Y, Nakazaki M, Nagahama H, Oka $\mathrm{S}$, et al. Intravenous infusion of mesenchymal stem cells promotes functional recovery in a model of chronic spinal cord injury. Neuroscience 2016; 335: 221-31.

61 Fischer UM, Harting MT, Jimenez F, Monzon-Posadas WO, Xue H, Savitz SI, et al. Pulmonary passage is a major obstacle for intravenous stem cell delivery: the pulmonary first-pass effect. Stem Cells Dev 2009; 18: 683-92.

62 Caron I, Rossi F, Papa S, Aloe R, Sculco M, Mauri E, et al. A new three dimensional biomimetic hydrogel to deliver factors secreted by human mesenchymal stem cells in spinal cord injury. Biomaterials 2016; 75 : 135-47.

63 Kim YC, Kim YH, Kim JW, Ha KY. Transplantation of mesenchymal stem cells for acute spinal cord injury in rats: comparative study between intralesional injection and scaffold based transplantation. J Korean Med Sci 2016; 31: 1373-82.

64 Ruff CA, Wilcox JT, Fehlings MG. Cell-based transplantation strategies to promote plasticity following spinal cord injury. Exp Neurol 2012; 235: 78-90.

65 Muheremu A, Peng J, Ao Q. Stem cell based therapies for spinal cord injury. Tissue Cell 2016; 48: 328-33.

66 Ahuja CS, Fehlings M. Concise review: bridging the gap: novel neuroregenerative and neuroprotective strategies in spinal cord injury. Stem Cells TransI Med 2016; 5: 914-24. 